\title{
Effectiveness of the Devolved Primary Health Care Gatekeeper System in Machakos County, Kenya
}

\author{
Desire Aime Nshimirimana ${ }^{1, *}$, Wanja Mwaura-Tenambergen ${ }^{1}$, Donald Kokonya ${ }^{2}$, Maureen Adoyo ${ }^{1}$ \\ ${ }^{1}$ Department of Health Systems Management, School of Medicine \& Health Sciences, Kenya Methodist University, Nairobi, Kenya \\ ${ }^{2}$ Department of Mental Health, School of Medicine, Masinde Muliro University of Science \& Technology, Kakamega, Kenya
}

Email address:

nshima2007@yahoo.fr (D. A. Nshimirimana),Wanja.tenambergen@gmail.com (W. Mwaura-Tenambergen), dkokonya@yahoo.com (D. Kokonya),maureenadoyo.kemu@gmail.com (M. Adoyo)

${ }^{*}$ Corresponding author

\section{To cite this article:}

Desire Aime Nshimirimana, Wanja Mwaura-Tenambergen, Donald Kokonya, Maureen Adoyo. Effectiveness of the Devolved Primary Health Care Gatekeeper System in Machakos County, Kenya. American Journal of Health Research. Vol. 4, No. 4, 2016, pp. 91-99. doi: 10.11648/j.ajhr.20160404.14

Received: June 12, 2016; Accepted: June 22, 2016; Published: June 30, 2016

\begin{abstract}
The low health outcomes and inequities problems in developing countries are due to ineffective gate keeping at the Primary Health Care (PHC) level, non-adherence to policy and dysfunctional health infrastructure. This study was conducted at 100 PHC centres sampled using Taro Yamane formula, in Machakos County, Kenya, from March to May 2015. It involved 8 gender-based focus group discussions (FGDs) with patients and their caretakers. Qualitative and quantitative data were collected from emancipated children and adults aged 15-65 years excluding the disabled due to data integrity issues. The Statistical Package for Social Science (SPSS) version 20.0 and Atlas.ti 7 software were used for data analysis. Correlation was done using the Spearman rho test and significance was set at $<0.05$. A questionnaire return rate of $83 \%$ was achieved of whom $84.3 \%$ were nurses $(\mathrm{p}<0.001)$ nurses and $15.7 \%$ were diploma holders in clinical medicine (clinical officers). The health workers were young $(\mathrm{P}<0.001)$ and married $(\mathrm{p}<0.001)$. A proportional relationship $(\mathrm{rho}=0.383, \mathrm{p}<.001)$ existed between the number of out-patients received and cases referred to hospitals. Most gatekeepers were ignorant $(\mathrm{p}=0.04)$ about the Policy on the patients' referral yet they did not officially refer patients $(80.7 \%)$. Most (63.5\%) of the hospitals receiving self-referrals did not ask for referral letters. Policy and referral letters were found to be necessary $(p=0.004)$. The gatekeepers' non-adherence to policy, lack of laboratory services and shortages of drugs contributed to self-referral by patients, creating a burden on the resources for healthcare, resulting in inefficiency at the PHC level. This study recommends a review of the gatekeeping system at the PHC level, capacity building, quality assurance, redefinition and strengthening of the office of the gatekeepers, regularization of supplies and reinforcement of the patient referral policy, staff motivation and best practices in customer care.
\end{abstract}

Keywords: PHC, Gatekeeper, Effectiveness, Policy, Rationalization

\section{Introduction}

Health outcomes are low among many developing countries and the inequities in health status are challenges from which no country in the world is exempt [1]. Primary Health Care (PHC) is viewed by many countries to be the backbone of a rational health care system [2]. The PHC serves as the foundation for building a strong healthcare system that ensures better health outcomes [3]. It was envisaged to be the first level of contact of individual patients, their families and communities with the national health systems, bringing health care as close as possible to the people and constituting the first element of a continuing health care process [4]. The PHC programme was designed to address the main health problems in the community accessibly and affordably, through promotive, preventive, curative and rehabilitative health care [5].

Good health policies exist at the national level of the Kenyan Health System but challenges lie in the implementation process [6]. Some Countries have successfully implemented their policies [7]. Among industrialized nations, the PHC orientation of countries' 
health systems are associated with lower costs of care, higher satisfaction of the population with its health services, better health outcomes and efficient use of resources [8]. The British National Health Service (NHS) established Primary Care Trusts (PCT) that integrate primary and hospital based health care and constitute the bulk of the NHS budget [9]. The Newly developed nations such as Brazil have also implemented national-level strategies to increase access to their PHC services [10]. An integrated system of PHC and gatekeeper system is crucial for strengthening $\mathrm{PHC}$ and achieving universal health coverage through overall efficiency in resources utilization [11].

The rationale of gate keeping is usually backed by three arguments: the need to ensure that patients receive appropriate health care, budget restraints and justice in distributive care [12]. The gatekeeper system addresses the important question of how to prevent people from getting lost in healthcare service delivery [13]. Many physicians in different countries have accepted both the role and the designation of the system [14]. Different specialties including nursing are functioning as gatekeepers: a recent study in the USA showed that $36 \%$ were in general internal medicine, $26 \%$ in internal medicine subspecialties, $23 \%$ in general paediatrics, $7 \%$ in paediatric subspecialties, and $5 \%$ in family medicine [15]. In nine out of 15 (9/15) European countries, PHC workers have been given a role as either complete or partial gatekeepers for specialist or hospital care [16]. The processes by which the PHC and the secondary health care (SHC) operate in improving health in a related manner lies at least in part in the gatekeeper role [17]. The first-contact feature of the PHC requires that patients do not visit the SHC facilities without referral notes from their preferred PHC service providers [18]. The SHC are greater users of tests and procedures and all such interventions have a risk of iatrogenic complications, the interposition of $\mathrm{PHC}$ is protective to patients in reducing both unnecessary procedures and adverse outcomes [19].

Canada has a more balanced PHC-specialist physician ratio than the United States of America (USA), with only $10 \%$ more secondary health care than the PHC physicians, in contrasts to over $50 \%$ more in the USA $[4,20]$. China is among the countries that inspired the PHC, focusing its attention to the rural health care and the use of local people called "barefoot doctors" locally referred to as community health workers (CHWs) to provide the first line health care [21]. Thailand adopted a "Basic Needs" approach in the 1970 s and established a health care system based on an alliance between the government and NGOs that integrated their PHC programs into other development programs [21, 22]. This alliance produced better health outcomes [23]. The Newly industrialized nations such as Brazil implemented national-level strategies to increase access to their PHC system [24]. An integrated system of the PHC and gatekeeper systems are crucial for strengthening the PHC and achieving universal health coverage (UHC) through overall efficiency of the PHC services [25]. The Kenya Health Policy 2012-2030 identifies the need to strengthen the orderly patient referral system as a way of improving efficiency in the Kenyan health system and improving patient outcomes. The lack of accountability to the needs of patients resulted in patients bypassing lower level health facilities (PHC) where quality was perceived to be lower, resulting in overcrowding and overwhelming of the higher-level health facilities [26]. Bypassing the PHC facilities was reported to be a challenge to the patients' referral system by the Ministry of Health (MOH), Kenya [27]. Machakos County, Kenya, was chosen for this study because the County government (under whose mandate falls the PHC program Tier 2) had heavily invested in the health sector including purchase of 80 ambulances to strengthen the patients' referral system in accordance with the principles of gatekeeper system [28]. Furthermore, the county government rolled out a strategy for patients' referral to enhance access of patients at PHC level to higher-level skills at Tier 3 [29]. The practice of bypassing the PHC services contributed to a large proportion of undesirable patients at Tier 3 (Sub-County Hospitals) who ideally, would have been well catered for at Tier 2, the PHC level [30]. The action in itself creates unforeseeable and unplanned expenditure in resources utilization and human resources deployment. This was conducted through assessment of the implementation of the national policy on gatekeeper system that influences rational use of resources in Machakos County, Kenya. The purpose of this study was to create and increase understanding, importance and influence of the gatekeeper policy implementation at the PHC level (Tier 2) for efficient use of available resources in Machakos County, Kenya. This study therefore, is a timely evidence-based guide and a contribution to the reinforcement of the County Government Health Services through gatekeeper system to realize efficiency and worthy returns from the heavy investment in the County Health Sector, Machakos County, Kenya.

\section{Methods}

This was a convergent, parallel and mixed methods descriptive cross sectional study design that employed both qualitative and quantitative data collection techniques [31]. This study was conducted over a 3-month period from January to March 2015 among the public health facilities in Machakos County, Kenya. The study population comprised of managers of Health Centres and dispensaries (gatekeepers) at Tier 2 (PHC) and patients at Tiers 3 (Hospitals). The study also conducted key informant interviews (KIIs) on the policy custodians at the County level, among them, the Chief Officer of health, the Director of Preventive and PHC services and the Medical Superintendent of the secondary level health facilities (regional referral hospital). The County Government of Machakos, with a total population of 150,041 had 99 dispensaries, 22 health centers and 4 sub-county hospitals at Tier 3 and one Tier 4 county referral and teaching hospital [32]. Therefore, there were121 primary health care (PHC) managers presiding over dispensaries and Health Centers. Using the Taro Yamane formula (1973), a 
minimum sample was calculated at 93 health managers and rounded off to 100 to cater for a possible $5 \%$ non-response. A maximum of 12 and a minimum of 8 patients constituted a focus group for discussion (FGD). For each hospital, 2 FGDs among patients and care takers (by gender and age) were conducted. The FGDs were conducted using the standard guidelines by the researcher administering the questions and a trained assistant recording the proceedings and responses on audio equipment to facilitate replay thereafter. Primary data was captured by administration of key informant interviews (KII) to health mangers and FGDs to patients and their caretakers. The researcher administered open-ended questions to the key informant interviewees (KII). Responses from the KIIs were instantly captured in notebooks. At each sub-county hospital, two FGDs were conducted, among patients and their caretakers. All the study participants who were informed and had voluntarily signed their consent forms participated in this study and all adult participants aged 18-65 years and emancipated children responded to the questions. The emancipated children (caretakers) aged 15 years and above and fully responsible for the patients they accompanied to the health facilities, qualified to participate in this study. All qualified persons who had not voluntarily signed the consent forms; children below 15 years of age and adults above 65 years of age were excluded from this study. The study excluded the physically ill and mentally incapable patients for purposes of data validity and integrity. Other exclusions were patients brought in as emergency cases and the very sick. Quantitative data was double entered using Epi data to minimize errors and exported to the Statistical Package for Social Science (SPSS) version 20.0 for data analysis. Data analysis involved mainly descriptive statistics while qualitative data was transferred to Atlas.ti 7 software for analysis. Different and mixed methods were used in the development and management of data (triangulation) to enhance data accuracy, dependability, repeatability, replicability and generalizability. Data display was organized and summarized in tables, graphs and summary measures. Correlation was done using Spearman rho test and significance was set at $<0.05$.

\subsection{Duration of Work at the Current Facility}

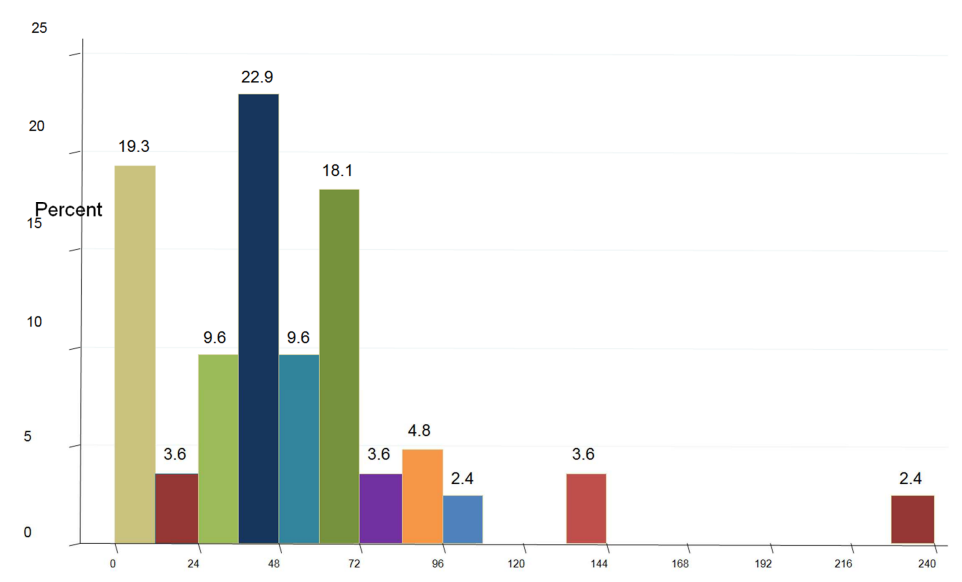

Figure 1. Duration of Work at the Current Facility $(N=83 \%)$.

\section{Findings}

\subsection{Socio-demographic Characteristics $(n=83)$}

Out of the 100 questionnaires administered to the study participants, 83 responses were received, giving a response rate of $83 \%$. Of the 83 valid responses, a large majority $(84.3 \%)$ were nurses and $15.7 \%$ were diploma holders in clinical medicine (clinical officers). This staff deployment pattern was in tandem with the known proportion of nurses to clinical officers in Kenya. The results were also a true reflection of the dominance of the nursing health managers at the PHC facilities in Kenya. This study used a statistical test (Chi-square) at $95 \%$ confidence interval with a $5 \%$ margin of error. The variables were statistically significant at $\mathrm{p}$-value of 0.05 or less.

Though there were more (59\%) female gatekeepers than males $(41 \%)$, the gender difference was not statistically significant $(p=0.124)$. A predominantly young, energetic and significant $(\mathrm{p}<0.01)$ management workforce aged $26-45$ years dominated (73\%) gate keeping in Machakos County, Kenya, as opposed to the inexperienced (7.2\%) below 25 years of age and the experienced (19.3\%) above 46 years of age. This implies that the Tier 2 level of health care in Machakos County needs experience to boost the institutional memory. The management of gate keeping system was by and large $(p<0.001)$ in the hands of married $(80.7 \%)$ health care providers compared to the single (19.3\%) (Table 1).

Table 1. Socio-demographic characteristics $(n=83)$.

\begin{tabular}{|c|c|c|c|c|}
\hline Characteristics & Categories & Frequency & $\%$ & P-value \\
\hline \multirow{2}{*}{$\begin{array}{l}\text { Designation of the } \\
\text { health worker }\end{array}$} & Nurse & 70 & 84.3 & \multirow{2}{*}{$<0.001$} \\
\hline & Clinical officer & 13 & 15.7 & \\
\hline \multirow{2}{*}{ Gender } & Female & 49 & 59.0 & \multirow{2}{*}{0.124} \\
\hline & Male & 34 & 41.0 & \\
\hline \multirow{4}{*}{ Age } & $18-25$ & 6 & 7.2 & \multirow{4}{*}{$<0.001$} \\
\hline & $26-35$ & 33 & 39.8 & \\
\hline & $36-45$ & 28 & 33.7 & \\
\hline & $46+$ & 16 & 19.3 & \\
\hline \multirow{2}{*}{ Marital status } & Married & 67 & 80.7 & \multirow{2}{*}{$<0.001$} \\
\hline & Single & 16 & 19.3 & \\
\hline
\end{tabular}


A large proportion (94\%) of the health care service providers had been at their current stations of duty for less than 10 years, reflecting injection of new ideas compared to $3.6 \%$ who had worked at their current duty stations for 12 years while a few $(2.4 \%)$ longest serving health care providers had been at their current stations of duty for 20 years. Once again, institutional memory was threatened with a diminishing number of experienced and long serving gatekeepers which may be attributable to the complains raised by patients for bypassing the PHC centres (Figure 1).

\subsection{Policy and Implementation of Gatekeeper System $(n=83)$}

Ignorance $(67.5 \%)$ among gatekeepers about the National Health Policy on the patient referral system found out in this study may point a finger at a directed programme implementation approach. Only $32.5 \%$ of the Kenyan gatekeepers were informed about the national Gatekeeping Policy. This ignorance may have been a major contributing factor to the tendency of patients to bypass the PHC services to seek health care for preventable illnesses and minor ailments at hospitals in Machakos County. The gatekeepers and health managers in the study area acknowledged that there had been delays or partial information forthcoming from the national offices and the policies were almost non-existent at both the PHCs and SHCs health facilities. The majority $(80.7 \%)$ of the gatekeepers believed that referral letters were required to seek health care at higher health care levels and less than a fifth (19.3\%) believed that a referral letter was not required to visit a secondary health care facility (hospital).
These findings confirmed that the policies had been well distributed and awareness created among most of the gatekeepers in Machakos County, but interpretation, understanding and implementation might have been the problem. The majority $(63.5 \%)$ of the patients reported that no one asked for referral letters at sub-county hospitals and few health workers at county referral hospital asked for it. The patients also mentioned that at the PHC facilities, if they wanted to be referred to SHCs, there were no official referral letters given. They reported that they were requested to use their consultation booklets, which had insufficient and unconfirmed information about the causes of or justification for their referral. According to the patients, they believed that their outpatient review booklets served adequately as referral letters, though inadequate and less informative. The patients thought that referral letters were only required when referred to Kenya's national and referral hospital, the Kenyatta National Hospital (KNH) in Nairobi, Kenya's capital city. If official referral letters were not available at the PHC centres, the enforcement of the referral policy was not effective, yet referral tools where designed and made freely available at national level. This study found out that there was a relationship between the presence of policy requiring a patient to consult first at the PHC facilities and the need for referral letters to visit the SHCs $(p=0.004)$ in which more people were ignorant of the policy. The relationship between existence and implementation of the gatekeeper policy in health systems management implies that if a policy exists, it should be implemented to warrant its existence.

\subsection{Outpatient Workload and Referrals at PHCs in Machakos County}

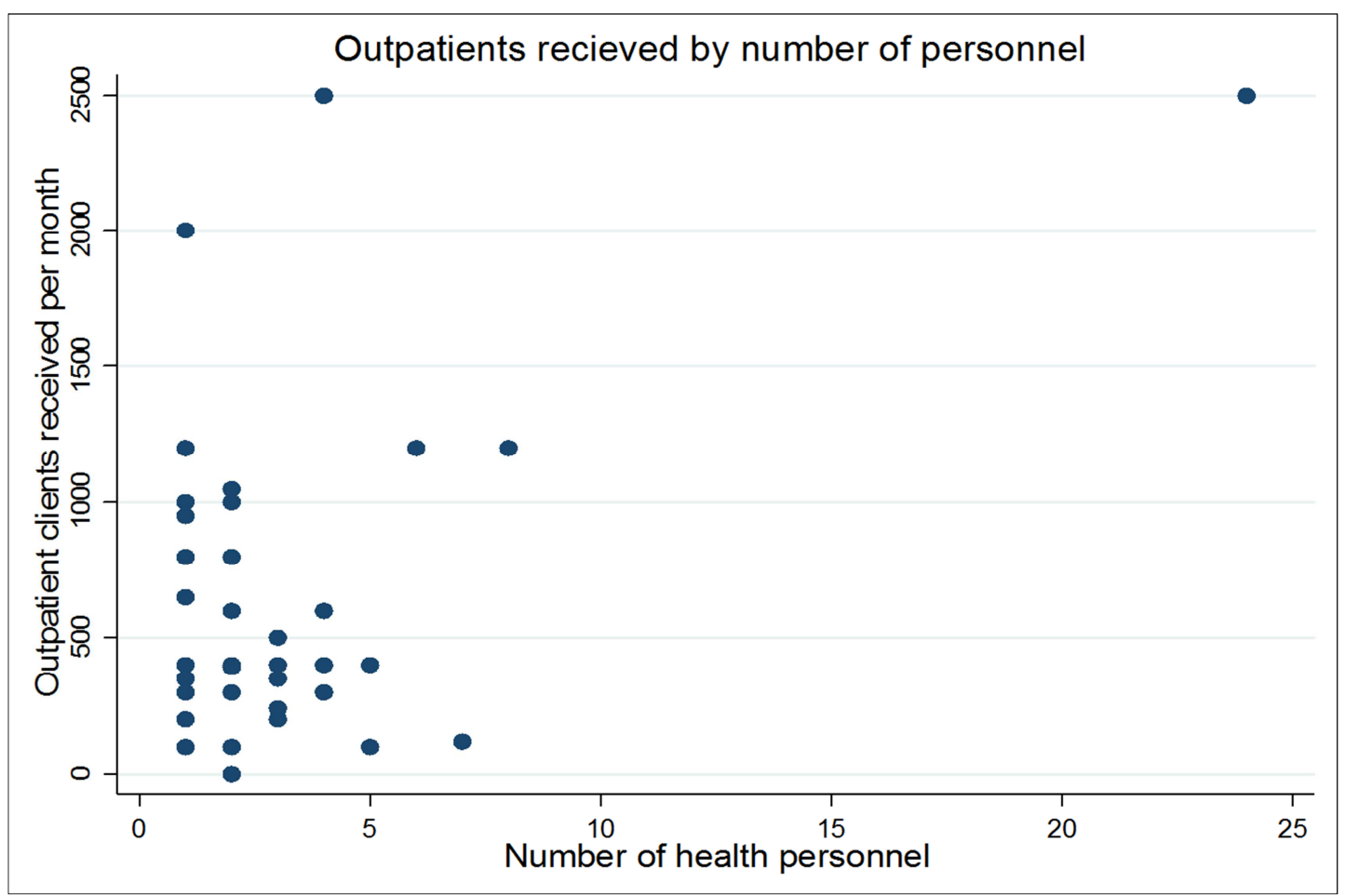

Figure 2. Correlation between Outpatients received by number of health personnel $(N=83)$. 


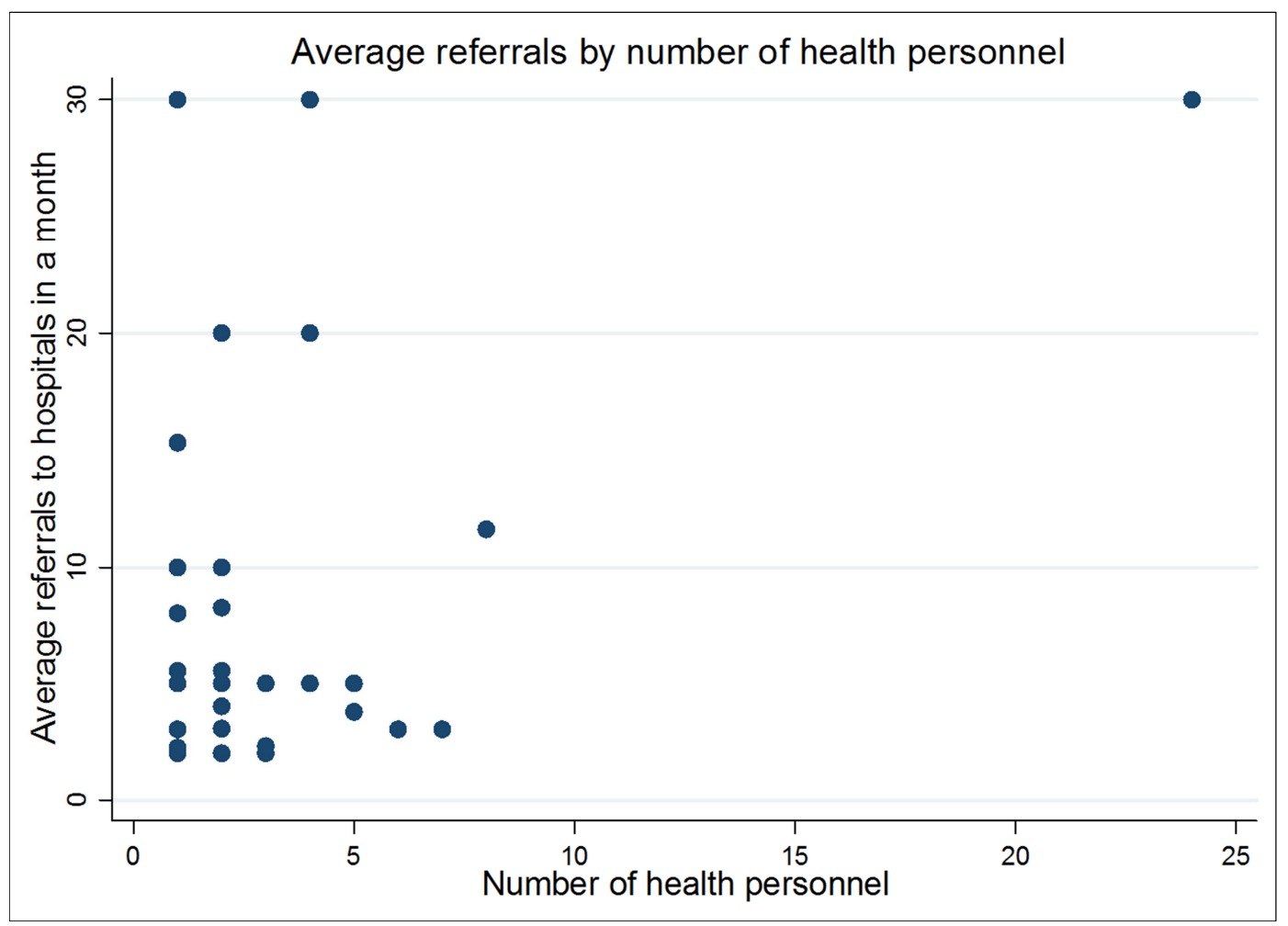

Figure 3. Correlation between average referrals and the number of health personnel.

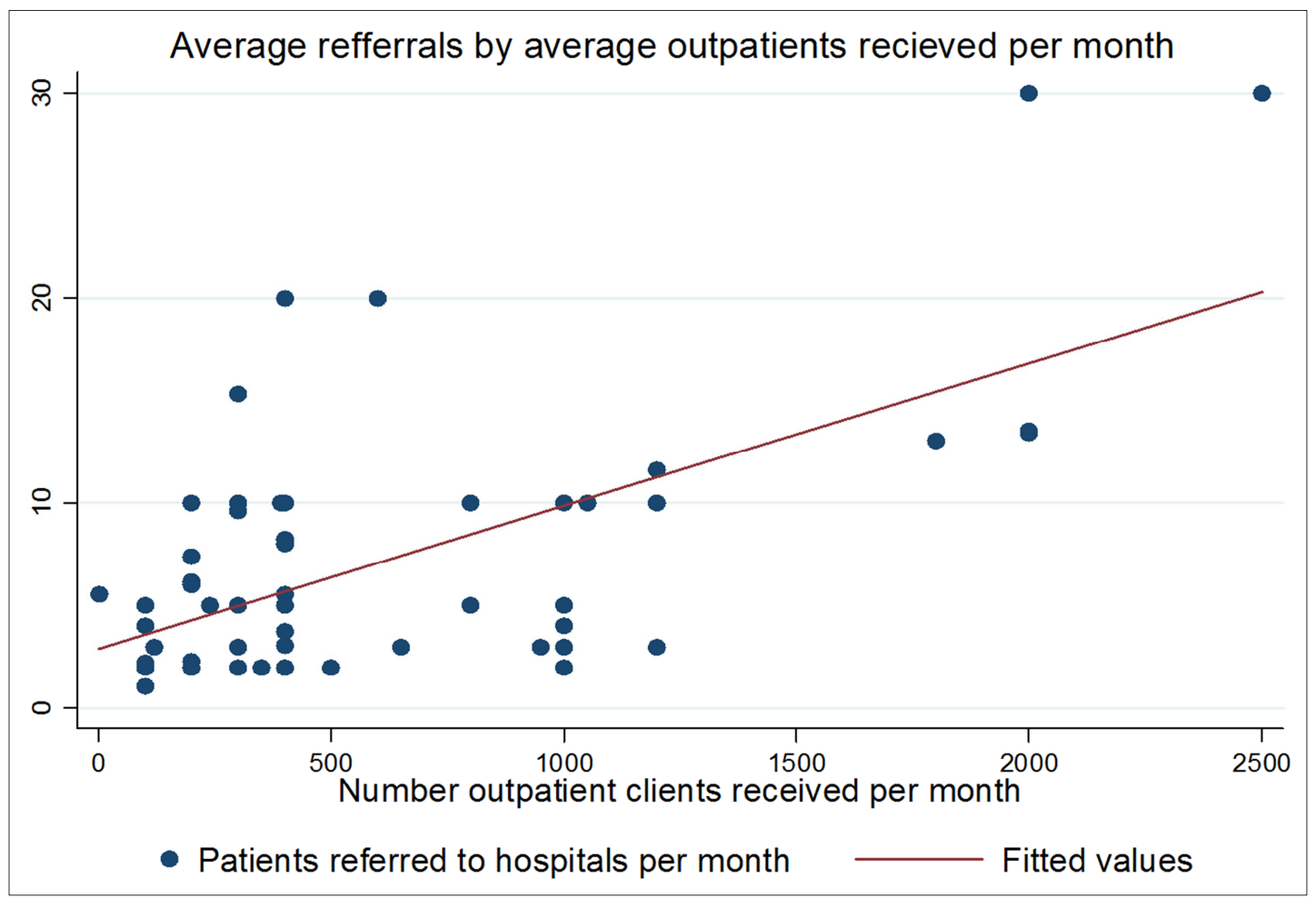

Figure 4. Correlation between number of referrals and outpatients at level2 $(N=83)$.

Due to inadequacy of data, gatekeepers were asked to estimate the outpatient workload/month at PHC centres in Machakos County and about a third (33.7\%) of the health facilities were reported to receive an estimated 250-500 patients per month ( average of 375 patients/month). Over
$60.2 \%$ of the PHCs received an average of 510 patients per month, an average of 17 patients per day. Just over two-fifths $(41.0 \%)$ of the PHC centres officially referred no more than 5 patients/month to hospitals. About $70 \%$ of the health facilities referred between 0 and 10 patients per month (average of 
5patients per month). Up to 15 patient referrals $(2.9 \%)$ per month/PHC facility accounted for an estimated $90 \%$ of all patient referrals from the PHC facilities. A paltry $8.3 \%$ of the PHC facilities referred from 15 to 30 patients $(5.9 \%)$ per month. Noting that an average of 17 patients attended the PHC per day, the referrals can be extrapolated to reflect maximum referral rates of approximately $3-6 \%$ per month of the monthly workload (Figure 2).

There was no association between the number of health personnel at any one time and average number of outpatients received (Spearman rho=-0.011, $\mathrm{p}=0.938$ ) (Figure 2) and number of referrals to hospitals (Spearman rho $=0.132$, $\mathrm{p}=0.368$ ) (Figure 3). There was a positive correlation (Spearman $\mathrm{rho}=0.383, \mathrm{p}<0.001$ ) between the number of referrals and outpatients received per month, implying a direct and proportional relationship between the number of outpatients and cases referred to level 3 (hospitals) health facilities. This means that a number of patients consulting at PHC centres were likely to be referred to SHC centres depending on the flow of patients and not otherwise. The more the flow of patients at PHCs, the more referrals to SHCs were done. This was a behavior that could have been avoided by providing incentives to nurses working at PHCs.

\section{Discussion}

The majority (84.3\%) of the gatekeepers (health managers) were female nurses compared to clinical officers, a finding consistent with an overview of the health systems in Kenya [33]. The majority $(71 \%)$ of these gatekeepers were young $(<45$ years) and inexperienced and they had been at their current stations of duty (94\%) of duty for less than 10years. These findings compared well with the findings at Mbagathi hospital, Nairobi and an Australian study on the length of employment of health workers at their work stations $[34,35]$. This implies that Machakos County was rich in injection with new ideas at the PHC level but it lacked experience and institutional memory that were important and perpetuated by older, experienced health workers for effective health services planning, consistency and continuity with the traditions in the health sector. Evidence that institutional memory was threatened at the PHC services delivery points in Machakos County, Kenya, was confirmed by the fact that $67.5 \%$ of the gatekeepers were ignorant about Kenya's National Patient Policy referral from PHC facilities to Tier 3 (hospitals). An inference based on these findings could be made that the $63.5 \%$ of the patients with preventable diseases who bypassed the PHC facilities in Machakos County, Kenya, to seek health care for non-preventable diseases at Tiers 3 and 4 which specialized in curative health care caused a major dissonance in the preparedness of hospitals to cater for preventable diseases, a manpower misallocation and misplacement, a supplies inequity and inequality, a management and emergency crisis, a resources misallocation, mismatch and misuse of resources, a surge and pressure by patients on the limited and incompatible resources at Tiers 3 and 4 and under-utilization of resources and services at the PHC level (Tier 2).
Though the gatekeepers (health managers) at the PHC level were aware $(80.7 \%)$ that patients at the PHC level needed referral letters to justifiably and appropriately seek health care services at hospitals (Tier 3 and 4) and that a national policy to that effect existed, then it could be inferred from these findings that the weak point was at implementation of the policy at the PHC and SHC levels, of which the policy was bestowed on gatekeepers at the PHC level, the majority of whom were female (59\%) among all nurses $(84.3 \%)$. This study also established that ignorance about the Kenyan National Patient Referral Policy among gatekeepers at the PHC centres was statistically significant $(\mathrm{p}=0.04)$, a further confirmation that the policy was not adequately and effectively cascaded to the PHC levels among the gatekeepers at the PHC level. Further findings in this study showed that; based on an estimated patient attendances of approximately 510/month at each PHC service delivery points for preventable diseases and a community ignorance level of about the national patient referral policy at $63.5 \%$, an inference could be made that the PHC facilities were under-utilized because the gatekeeping system was weak at policy implementation subsequent to which an estimated 510/month patients sought PHC services instead of $1,397 /$ month. The low attendance by patients at the PHC centres in Machakos County, Kenya, was exercabated by the high rates of patients bypassing the PHC centres and further 5 patients per month referred officially by the PHC centres. By extension, this weakness in gatekeeping was contributing to a proportional yet unexpected and unjustified burden (workload) at hospitals (Tiers 3 and 4)/hospitals in Machakos County, Kenya. Tiers 3 and 4 on the other hand, were equipped for preventable diseases but prepared for curative healthcare requiring higher level and specialized healthcare. Based on the submissions of the patients and their care takers on the one hand and the health managers (gatekeepers) at Tier 2 level of health services delivery, the reasons attributed to the low attendance of patients at Tier 2 included negative attitudes of health care providers at the PHCs level, inadequate and in some instances, lack of training and low motivation of gatekeepers at the PHC levels. These findings compared well with a study conducted in Tanzania [26]. The gatekeepers reported that overcoming the implementation challenges would entail patient education on the importance of the gatekeeper system, appropriate marketing of primary gatekeepers and primary care advocates and continued training in gatekeeping at PHC level. They reported that there was a need to promote gatekeeping in a health care system incorporating gradual and incentive-driven approaches instead of penalties to self referrals as the case is in other countries [2]. The findings of this study concurred with that of Egypt in the year 2010 in which about $50 \%$ of the respondents supported a full gatekeeper model. Due to lack of familiarity with gatekeeping system and use of penalties, they felt that it would be difficult to implement regulations because of some barriers such as; loss of faith in primary health care personnel by the general population, dearth of primary care workers with adequate training, low stature, lack of 
availability and resistance by specialists [36, 37]. Subsequently, the Israelis in 2000 , recommended gradually and incentive driven rather than regulations when implementing primary health care gatekeeper system. The results of this study are similar to the recommendations by a joint WHO/GIZ mission on social Health Insurance in Kenya in 2003 [38]. The positive correlation between outpatient visits and referrals implies that the more patients seen, the more referrals were done and the reasons behind were lack of laboratory services and drug shortages as the leading causes of referrals. These findings were similar to those demonstrated by Kahabuka et al., 2011. For the patient referral system to function properly all referral levels needed to be appropriately equipped (necessary laboratory equipment, personnel with correct skills mix, pharmaceuticals and transport), so that few emergencies be referred to the national hospital and nearest competent health facility in the nearest region [39]. These findings were consistent with those of Kruk et al. [30]. In order to minimise unnecessary referrals, it was preferable that sub-county hospitals and health centres be equipped with minimum technology (laboratory equipments and information systems), adequate and qualified staff [40].

\section{Conclusion}

Many patients with preventable and immunizable diseases in Machakos County, Kenya, bypassed the PHC centres (Tier 2) in preference for Tier 3 and 4 (hospitals)which specialized in curative health care causing a major dissonance in the preparedness of the hospitals in their efforts to cater for non-preventable diseases. It further caused a manpower misallocation and misplacement, a supplies inequity and inequality, a management and emergency crisis, a resources misallocation, mismatch and misuse, a surge and pressure by the Tier 2 workload on the limited and incompatible resources at Tiers 3 and 4 (hospitals) and under-utilization of resources and services at the PHC level. The weak point was found to be policy ignorance and implementation failure by gatekeepers at the PHC level. The positive correlation between outpatient visits and referrals implies that the more patients seen, the more referrals are done and the reasons behind it, according to the members in the FGD conducted and key informants were inadequacies of laboratory services and drug shortages as the leading causes of self-referrals. The reasons advanced went against the well-guided and informed Kenyan Health System by the policy on patients 'referral. A good number of health managers and clients (catchment population) were not aware of the existence of the policy, hence the need for trainings and capacity building on patients referrals in Machakos County. The factors behind the ignorance were found to be referral of patients with their outpatient attendance booklets instead of official letters that spurred on patients to consult hospitals directly. Though official referral letters were available at the PHC centres where applicable, they did not serve any useful purpose. The majority of health managers knew about gatekeeping system at the PHC levels and their roles in the implementation of the referral policy but it was not translated into practice, further justifying the need for redefining and strengthening of the gatekeepers' capabilities and capacities. The gatekeepers reported that they were willing to do more if incentives were offered to them, including trainings, adequate materials, supplies and medical equipment. This study therefore, recommends a review of the staffing norms and levels of service delivery at PHCs, capacity building, supervision and quality assurance, redefinition and strengthening of the office of the gatekeepers, regularization of supplies and reinforcement of the patient referral policy, staff motivation and best practices in customer care.

\section{Acknowledgements}

I sincerely acknowledge the research assistant (Raphael Mutiso) and the biostatistician (Elijah Kipkech Kipchumba) for contributing to data collection and analysis.

\section{References}

[1] Jamison T. D et al. Global health 2035: a world converging within a generation. The lancet 2013. San Francisco, USA. DOI: http://dx.doi.org/10.1016/S01406736(13)62105-4

[2] WHO. Primary Health Care: Now More Than Ever. World Health Report [internet] 2008. Geneva, Switzerland. Retrieved from http://www.who.int on $2^{\text {nd }}$ December 2014.

[3] Shi L. Impact of Primary Care. A focused review. Hindawi Publishing Corporation. Scientifica 2012. Retrieved from DOI http://dx.doi.org/10.6064/2012/432892.

[4] Rao M. and Pilot E. The missing link _the role of primary care in global health. Glob Health Action 2014, 7: 23693 http://dx.doi.org/10.3402/gha.v7.23693

[5] Hsieh C-R. V., Wu C-L. J., Wu N. T and Chiang L. T. Universal Coverage for Primary Health Care Is a Wise Investment. Evidence From 102 Low-and Middle-Income Countries. Asian Journal of Public Health [internet] 2013. Taiwan.

[6] Turin R D. Health Care Utilization in Kenyan Health System: Challenges and Opportunities. Student Pulse [internet] 2010 Vol.2 No 09. Northeastern University in Boston, Massachusetts

[7] Macinko J, Starfield B and Erinosh T. The Impact of Primary Healthcare on Population Health in Low - and Middle Income Countries. Journal of Ambulatory Care Management 2009 Vol. 32-issue 2-p 150-171. doi: 10.1097/JAC.0b013e3181994221

[8] Starfield B., Shi L. and Macinko J. Contribution of Primary Care to Health Systems and Health. The Milbank Quarterly [internet] 2005. Bethesda, USA. Retrieved from http://www.ncbi.nlm.nih.gov on $2^{\text {nd }}$ December 2014.

[9] Hale L. Integrated Health Care in England: Lessons for Ontario. The Change Foundation. Case Study on Integrated Health Care System. England [internet] 2009. Retrieved from www.changefoundation.ca on $25^{\text {th }}$ February 2016.

[10] Macinko J., Almeida C. and Klingelhoefer de Sa' P. A rapid assessment methodology for the evaluation of primary care organization and performance in Brazil. Health Policy and Planning 2007; 22: 167-177 doi:10.1093/heapol/czm008 
[11] Kousoulis A A, Symvoulakis K E and Lionis C. What Greece can learn from UK primary care experience and empirical research. British Journal of General Practice2012. England. DOI: 10.3399/bjgp12X656928

[12] Wael F S. Reforming Egypt's health system: is it that simple? BMJ 2006; 333:859. doi http://dx.doi.org/10.1136/bmj.333.7573.859-a

[13] HennessyJ. Federally Qualified Health Centers and Health Reform: Up to the Task? Northwestern Journal of Law and Social Policy [internet] 2013. http://scholarlycommons.law.northwestern.edu/njlsp/vol9/iss1/ 5

[14] Mash R., Almeida M., Wong W. C. W., Kumar R. and Pressentin B. K. The roles and training of primary care doctors: China, India, Brazil and South Africa. Human Resources for Health2015 13:93. DOI 10.1186/s12960-015-0090-7

[15] Blank L, Baxter S, Woods HB, Goyder E, Lee A, Payne N, et al. What is the evidence on interventions to manage referral from primary to specialist non-emergency care? A systematic review and logic model synthesis. Health Service Delivery Research 2015; 3(24). DOI 10.3310/hsdr03240

[16] Willems L. D. Balancing rationalities: gatekeeping in health Med Ethics 2001 27: 25-29 doi: 10.1136/jme.27.1.25 J

[17] Ridde V. Is the Bamako Initiative Still Relevant for West African Health Systems? International Journal of Health Services [internet] 2011. Vol. 41, Number 1/2011. New York, USA. Retrieved from http://baywood.metapress.com on $3^{\text {rd }}$ December 2014

[18] Kegleviü V. M. Effectiveness of Primary Health Care: in Memory of Barbara Starfield. Med Fam Croat2014 Vol 22, No2.

[19] Starfield B. Refocusing the System. The England Journal of Medicine [internet] 2008. Baltimore, USA. Retrieved from http://www.nejm.org on $2^{\text {nd }}$ December 2014.

[20] Luisa M Pettigrew M. L., Maeseneer De J., Anderson P. M., Essuman A., Michael R Kidd R. M. and Haines A. Primary health care and the Sustainable Development Goals. The lancet 2015 vol 386, No. 10009, p 2119-2121, 28 November 2015. DOI: http://dx.doi.org/10.1016/S0140-6736(15)00949-6

[21] Bhatia M. and Rifkin S: A renewed focus on primary health care: revitalize or reframe? BMC Globalization and Health 2010 6:13. doi:10.1186/1744-8603-6-13.

[22] Chatora R. R. and Tumusime P. Primary health care: a review of its implementation in sub-Saharan Africa. Primary Health Care Research and Development2004, pp 296-306 Vol. 5/Issue 04. Doi:http://dx.doi.org/10.1191/1463423604pc220oa

[23] Weel V. C and Maeseneer D. J. Now more than ever. World Health Assembly revisits primary health care. Primary Health Care Research \& Development [internet] 2009. Cambridge. Retrieved from http://journals.cambridge.org on $3^{\text {rd }}$ December 2014.

[24] Kruk E. M, Porignon D., Rockers C. P. and Lerberghe V. W. The contribution of primary care to health and health systems in low- and middle-income countries: A critical review of major primary care initiatives. Social Science \& Medicine 2010 vol.70, issue 6, pages 904-911. Doi: 10.1016/j.socscimed.2009.11.025.
[25] Gigli, S, Wright J, Raj F and Agarwal M. Performance Based Incentives to Strengthen Primary Health Care in Haryana State, India. Bethesda, MD: Health Finance \&Governance Project, Abt Associates Inc [internet] 2015. www.abtassociates.com

[26] Kahabuka C, Kvåle G, Moland M. K. and Hinderaker G. S. Why caretakers bypass Primary Health Care facilities for child care - a case from rural Tanzania. BMC Health Services Research 2011 11:315. doi:10.1186/1472-6963-11-315

[27] Ministry of Health. The State of the Health Referral System in Kenya: Results from a Baseline Study on the Functionality of the Health Referral System in Eight Counties. USAID and MEASURE Evaluation PIMA2013. Nairobi, Kenya.

[28] Bryan L., Conway M., Keesmaat T., McKenna S. and Richardson B. Strengthening sub-Saharan Africa's health systems: A practical approach. McKinsey \& Company [internet] 2010. Retrieved from http://www.mckinsey.com on $15^{\text {th }}$ April 2016.

[29] Luoma M, Doherty J., Muchiri S., Barasa T., Hofler K, Maniscalco L., Ouma C., Kirika R. and Maundu J. Kenya Health System Assessmen. Bethesda, MD: Health Systems 20/20 project [internet] 2010, Abt Associates Inc

[30] Kruk E M., Hermosilla S., Larson E and Mbaruku M G. Bypassing primary care clinics for childbirth: a cross-sectional study in the Pwani region, United Republic of Tanzania. Bull World Health Organ 2014; 92:246-253. New York, United States of America. doi: http://dx.doi.org/10.2471/BLT.13.126417

[31] Johnson B. and Onwuegbuzie J. A. Mixed Methods Research: A Research Paradigm Whose Time Has Come. Health Policy and Planning 2007; 22:167-177doi:10.1093/heapol/czm008

[32] The 2009 Kenya Population and Housing Census. Counting Our People for the Implementation of Vision 2030. Ministry of State for Planning, National Development and Vision 2030. Kenya National Bureau of Statistics 2010 vol IC. Nairobi, Kenya.

[33] Muga R, Kizito P, Mr. Mbayah M and Gakuruh T. Overview of the Health System in Kenya. Kenya Service Provision Assessment (KSPA 2004) [internet] 2005. Nairobi, Kenya.

[34] Musyoka N. F., Adoyo A. M. and Ongombe O. M. Influence of Job Description on Performance of Health Workers in Public Hospitals: A Case of Mbagathi Hospital, Nairobi City County. Science Journal of Public Health2016. Vol. 4, No. 2 pp. 88-93. doi: 10.11648/j.sjph.20160402.12

[35] Russell J. D, Wakerman J. and Humphreys S. J. What is a reasonable length of employment for health workers in Australian rural and remote primary healthcare services? Australian Health Review2013 37, 256-261. http://dx.doi.org/10.1071/AH12184

[36] Ward T. R. Implementing a gatekeeper system to strengthen primary care in Egypt: Pilot Study. Medical School, Australian National University, Canberra, Australia. Eastern Mediterranean Health Journal [internet] 2010 Vol 16 No 6.

[37] Liu J. J, Bellamy G., Beth Barnet B and Weng S. Bypass of Local Primary Care in Rural Counties: Effect of Patient and Community Characteristics. Annals of family medicine [internet] 2008 vol. 6, no. 2 Baltimore, Maryland. 
[38] Joint WHO/GTZ. National Social Health Insurance Strategy: Comments and suggestions of the joint WHO/GTZ mission on social health insurance in Kenya [internet] 2003. Nairobi, Kenya.

[39] Ministry of Health. Kenya Health Sector Referral Implementation Guidelines $1^{\text {st }}$ Edition. Division of Emergency and Disaster Risk Management [internet] 2014. Nairobi, Kenya. http://www.health.go.ke Visited on $24^{\text {th }}$ March 2016.

[40] Ministry of Health. National Referral Policy. Ministry of Health and Social Services. Directorate: Tertiary Health Care and Clinical Support Services 2013. Windhoek, Namibia. 